\title{
La publicidad alimentaria en la campaña de Navidad
}

The Food

Advertising in

the Christmas

Season

\section{Paloma Piqueiras Conlledo}

Universidad Complutense de Madrid piconlledo@gmail.com

Alba Tortosa Vicente

Universidad Complutense de Madrid albag.tortosa@gmail.com
Piqueiras, P.y Tortosa, A., C. (2015). La publicidad alimentaria en la campaña de Navidad.

Revista Internacional de Investigación en Comunicación aDResearch ESIC. No $11 \mathrm{Vol} 11$.

Primer semestre, enero-junio 2015. Págs. 78 a 95

DOI: 11.7263/ADRESIC.011.005 
En nuestro mundo, la publicidad tiene una influencia indudable: determina los productos que elegimos y nuestras opciones de consumo, incluso cuando se trata de alimentación ya que, en buena medida, comemos aquello con lo que los anunciantes nos bombardean. Por ello, las características de la información suministrada a través de la publicidad van a ser cruciales.

Los mensajes de la publicidad cobran gran importancia durante la época de Navidad; las compras se triplican y las reuniones familiares van a marcar un periodo en el que los productos alimenticios adquieren, junto con los regalos, el mayor protagonismo. Por ello, muchos de los anunciantes, tanto del sector alimentario como de otros sectores, tratan de introducir en sus spots diversos recursos y estereotipos navideños para que, a

Clasificación JEL: M31, M37

Palabras clave:

Anuncios,

televisión,

Campaña Navideña,

Estereotipos,

Alimentación,

Publicidad través del camino de la emoción, los consumidores se decanten por una u otra marca. Este trabajo tiene como objetivo determinar qué patrones, si es que los hubiera, utilizan los anunciantes de productos alimenticios en la campaña navideña.

Con este propósito hemos realizado un análisis de contenido de 127 anuncios emitidos en Telecinco la semana previa a Navidad. Los resultados, que han sido obtenidos de la codificación de esas emisiones, concluyen que realmente existe una serie de patrones similares utilizados en las campañas navideñas. Entre los elementos más utilizados puede destacarse el uso del árbol de Navidad o la reunión en torno a una mesa, siendo desigual la utilización que de ellos hace la publicidad de productos estacionales y no estacionales.
JEL Classification:

M31, M37

Key words:

Adverts,

television,

Christmas Campaign,

Stereotypes,

Food,

Advertising
In our world, advertising has an undeniable influence: determines the products we choose and our consumer choices, even with regard to food. Therefore, the characteristics of the information provided through advertising will be crucial.

This message is of great importance during the Christmas season, shopping triples and family gatherings will mark a period in which foodstuffs acquire, along with gifts, most prominence. That is why many advertisers (both the food industry and other sectors such as perfumes, toys ...) try to introduce into their various resources and holiday spots to stereotypes, through the way of excitement, consumers decant for either product. This work aims to determine what patterns, if any, used by advertisers of food products in the Christmas season.

For this reason has been done a content analysis on 127 Telecinco ads broadcasted the week before Christmas. The results, which were obtained from the encoding of these broadcasts, conclude that there are similar patterns used in the Christmas campaigns. Among the most used items can be highlighted the use of the Christmas tree or the gathering around a table, still unequal use made of them advertising seasonal and nonseasonal products. 


\section{Introducción}

El término Sociedad de la Información ha cambiado la forma de entender el mundo y de relacionarse al situar al ser humano en un contexto global en toda su expansión. Sin que hayamos averiguado aún las consecuencias de dicha transformación, ya empezamos a ser conscientes del impacto de las tecnologías y las corrientes de información e, incluso, podemos llegar a decir que el desarrollo de lo audiovisual es el hito más importante de nuestra era.

En este punto es prácticamente imprescindible hacer un alto en el camino y referirse a la publicidad. Su capacidad de intervención e influencia en la vida cotidiana es extraordinaria y por ello, su contenido ha sido fuente de estudio constante en el ámbito de la comunicación: desde sus inicios, cuando se centraba en hablar de los atributos de los productos, hasta su orientación actual basada en una «asociación entre sus productos y los valores sociales, personas, lugares o ideas que se encuentran en boga en cada momento» (León, 1991, p.1.054).

La publicidad juega, por tanto, a transmitir y crear emociones, «mover los sentimientos y tratar de convencer al receptor mediante las asociaciones agradables» a la vez que «resalta las ventajas inmateriales» (Marccía, 2000, pp. 123-124).

A partir de sus estímulos acaba por conformar un imaginario colectivo, es decir, una «determinada forma de entender el mundo y las relaciones entre las personas que lo habitan, entre las diferentes culturas del planeta» (Fueyo, 2006, p.28).

La presente investigación, guiada por la necesidad de conocer la estrategia publicitaria, trata de detallar pormenorizadamente los elementos comunes, si los hubiera, de los anuncios navideños a través de un objeto de estudio específico.
Consideramos que la Navidad es un periodo ideal para entender ciertos factores publicitarios ya que, como explica Ángel del Pino (1991, p. 242) «la publicidad ha hecho que esas fechas del calendario se estereotipen», multiplicándose así los «anuncios felices, coloristas, musicales y llenos de buena voluntad hacia las gentes».

El resultado está basado en la recopilación y estudio de anuncios televisivos, emitidos en Telecinco durante la tercera semana del mes de diciembre de 2013 y en la última franja del horario de mañana.

\section{Metodología}

\section{Determinación del objeto de estudio}

Como se ha señalado anteriormente, esta investigación se ha realizado a través del estudio de anuncios de comida emitidos en Navidad (del 17 al 24 de diciembre de 2013) en Telecinco durante la última franja horaria de la mañana (11:30 a 14 horas). La elección de este horario ha estado basada en el estudio de la revista Ocu-Compra Maestra (OCU, 2007, p. 30) que indica que la emisión de este tipo de anuncios es más generalizada en esta parte del día:

«Se emiten muchos más anuncios de comida por la mañana que en las otras franjas horarias. Por otro lado, resulta evidente que los publicistas buscan ajustarse a la audiencia que ve la tele en cada momento, y van ajustando el «menú» que ofrecen en sus anuncios en función del horario de emisión (...) En la franja de emisión que va desde las 7 horas a las 14 horas (teóricamente el horario de mañana comienza a las $2 \mathrm{~h}$, pero antes de las $7 \mathrm{~h}$ no hay spots tradicionales), además de golosinas y chocolates, se proponen postres lácteos, bollos, cereales y aperitivos. Normal- 
mente a esta hora ven la tele quienes se ocupan de la casa (y de la compra)».

Por su parte, la decisión de estudiar Telecinco se justifica con el informe de televisión presentado por el Observatorio aea de la Publicidad (2012, p.2):

- Telecinco ha sido la cadena que más Resto de Emisión ${ }^{1}$ ha tenido en el cómputo total del año, con un 19,9\%. Este dato es el más bajo anotado por la cadena en los últimos 5 años.

- «La cadena que más Publicidad ha emitido ha sido Telecinco, con 3 horas y 8 minutos diarios, seguida de La Sexta con una media de 2 horas y 55 minutos y de Cuatro con 2 horas y 51 minutos. Antena 3 fue la cadena nacional privada que menos Publicidad emitió con una media de 2 horas y 42 minutos diarios».

Diversos autores (Byrd-Bredbenner, 2002; Nash, Pine y Messer, 2009, Hamilton-Ekeke y Thomas, 2007; St-Onge, Keller y Heymsfield, 2003) han estudiado la importancia de la comunicación a través de la televisión como vía de influencia en las actitudes, comportamientos y valores de los consumidores. De hecho, existen algunas publicaciones (Jaeger 2006; Just y Payne, 2009) que aseguran que la elección entre un tipo de producto u otro está motivada por los anuncios de alimentación en televisión. Un ejemplo de ello es cómo la publicidad alimenticia influye en los hábitos de consumo del telespectador, habiéndose constatado que el público

1 El citado estudio entiende como Resto de Emisión a: avances de programación, autopromoción, teletienda, sobreimpresiones, patrocinios, telepromociones, spots convencionales y otras nuevas formas publicitarias. más vulnerable son los niños (Emma J. Boyland y Jason C.G. Halford, 2012).

Resulta curioso confirmar que este medio siga siendo el canal de comunicación más potente (Abbatangelo-Gray, Byrd-Bredbenner y Austin, 2008), incluso en la era tecnológica. Sorprende aún más que esa influencia televisiva se materialice sobre todo en el sector alimentario y de bebidas (Eagle, Bulmer, De Bruin y Kitchen, 2004; Henderson y Kelly, 2005; Story y French, 2004).

Respecto al periodo navideño, los juguetes (Rubio, 2011; Consejo Audiovisual de Andalucía, 2007 y 2009; Ferrer, 2007) han sido los primeros blancos de estudio debido al enorme impacto que suponen en la mente de los menores. Así mismo, tampoco han faltado investigaciones de marcas concretas como Coca-Cola, Nestlé, turrones, Lotería Nacional de Navidad o Freixenet. Junto a estos, también podemos encontrar otras de tipo cognitivo (Cortés, 2008) que han tratado de explicar la importancia de la transmisión de significados racionales y emocionales, atendiendo a un conocimiento superficial y a significados más profundos.

Una de las investigaciones más recientes la ha realizado la agencia de publicidad 101 sobre 'La evolución de los anuncios navideños en España' (2011). Este estudio confirma que los clichés publicitarios en Navidad se han mantenido con el tiempo, aunque algunos de ellos muestran año tras año la evolución de la sociedad española. De hecho, los creativos y marcas consideran estos tópicos como la forma más eficiente para atraer a los clientes en estas fechas de «consumo por excelencia». Según este informe, más del 90\% por ciento de los anuncios de la campaña navideña incluyen nieve, niños, familia o una historia entrañable que acaban por perfilar un argu- 
mento recurrente. Así mismo, esta agencia asegura que es la publicidad la que ha configurado la idea que tenemos sobre estas fiestas.

En esta misma línea, Silvia Sivera (EFE/Barcelona, entrevista, 25 de diciembre de 2013), profesora de Publicidad y Relaciones Públicas de las Universidad Oberta de Catalunya (UOC), afirma que sin los anuncios de turrones, cavas, juguetes y perfumes «la Navidad sería menos Navidad". Además, considera que la publicidad en estas fechas «reproduce estereotipos" siendo los tópicos fundamentales de la Navidad éstos: «la felicidad por los reencuentros, por estar toda la familia unida, por regalar y que te regalen".

Por su parte, Simon Learman, director creativo de McCann Londres, realiza un análisis exhaustivo (2011) de los denominados «clichés" propios de la publicidad durante la campaña de Navidad. Learman opina que durante esta época se cambia el enfoque de comunicación y el uso de este tipo de estereotipos se acentúa. Esto lleva a dificultar que una marca destaque sobre el resto dada la similitud de los enfoques publicitarios utilizados (uso de famosos, escenas míticas de Navidad, evocar a la familia y la fiesta, etc.). Ante ello, la solución que plantea es que sean las grandes marcas, aquellas que ya estaban llevando una buena campaña publicitaria, las que se atrevan a utilizar estos patrones navideños, siempre y cuando utilicen su propia idea y la adapten de forma adecuada, encontrando el equilibrio entre clichés, emociones y una buena idea de comunicación.

En cuanto al material a analizar y siguiendo el hilo de los tres tipos de unidades de análisis que Krippendorff (1990) indica, podemos concretar:

- Unidades de muestreo: anuncios de comida de la última franja del horario de mañana.

- Unidades de registro: patrones navideños.
- Unidades de contexto: anuncios que van antes y después del analizado.

\section{Determinación de los objetivos y tipo de estudio}

Existen tres propósitos fundamentales en esta investigación:

- Recoger varios ejemplos de anuncios alimentarios emitidos durante la campaña navideña.

- Analizar y clasificar los elementos relacionados con esta época del año.

- Generar un informe acerca de los resultados obtenidos.

Según el material de estudio se trata de un análisis descriptivo, ya que tiene por objetivo describir y catalogar o identificar una realidad en base a la definición de categorías.

En función del material objeto de estudio estamos ante una investigación horizontal, porque consta de un corpus amplio formado por una gran cantidad de material susceptible de ser analizado. A su vez es transversal, pues está basada en la selección de muestras del material para comprobar los distintos elementos que lo componen.

La medición de los datos se ha realizado de forma cuantitativa y cualitativa, mientras que la evaluación es frecuencial (tiene en cuenta el número de veces que aparecen los patrones) y, a su vez, no frecuencial (se analiza la presencia o ausencia de la unidad en el objeto de análisis) de forma distribucional, o lo que es lo mismo, de forma estadística.

\section{Hipótesis}

- H1- Los anuncios navideños de alimentos recurren a situaciones en el hogar y tratan de evocar sentimientos familiares a través de unos patrones establecidos. 
- H2- Existe una diferenciación por estacionalidad. Aquellos que tienen un consumo anual no recurren a patrones propios de la Navidad.

- H3- El grueso de la publicidad durante estas fechas señaladas está ocupado por anuncios de productos estacionales.

\section{Determinación de las reglas de codificación}

Tal y como detalla Holsti (en Bardin, 1986, p. 78), la codificación es el producto por el que los datos brutos se transforman en unidades que permiten una descripción precisa de las características de un contenido. De estos son reseñables las siguientes (Bardin, 1986):

- Presencia (1)/Ausencia (2). Se han determinado dos categorías para distinguir aquellos anuncios que poseen elementos navideños y los que no. De esta forma, se codifica con el número uno (1) la presencia y con el dos (2) la ausencia.

- Frecuencia. Se ha tenido en cuenta la cantidad de veces que aparecen dichos elementos y la repetición del mismo spot a lo largo del tiempo analizado.

- Intensidad. El tono de la comunicación. Además de los elementos visuales se han contabilizado los sonoros y textuales.

En el presente estudio se han añadido otras guías a las establecidas por Bardin, de forma que las reglas de codificación han quedado determinadas de la siguiente manera:

\section{Formales}

1. Número del anuncio

2. Producto de alimentación

1. Estacional

2. No estacional

3. Marca

4. Duración

\section{De contenido}

5. Existencia de elemento navideño

1. Presencia

1. Visual

1. Árbol

2. Luces de Navidad

3. Mesa para comida/cena de Navidad

4. Nieve

5. Regalos

6. Papá Noel

7. Trineo

8. Renos

9. Acebo

10. Muérdago

11. Reyes Magos

12. Chimenea

13. Familia

14. Adornos

1. Velas

2. Espumillón

3. Bolas

4. Planta de Navidad

5. Calcetines

6. Corona de Navidad

7. Lazo de Navidad

8. Gorro de Papá Noel

2. Audio

3. Texto

2. Ausencia

\section{Determinación del sistema de categorías}

Laurence Bardin (1986, p. 90) la define como «una operación de clasificación de elementos constitutivos de un conjunto por diferenciación, tras la agrupación por analogía, a partir de criterios previamente definidos". No obstante, como no existe una clasificación estándar lo que se busca con esta sistematización es mostrar lo co- 
mún entre las unidades de análisis, que es lo que permite obtener unos resultados.

En base a esto, la clasificación que se ha llevado a cabo en esta investigación se sustenta en:

- Inventario: Aislamiento de los elementos objeto de estudio. En la presente investigación se han tenido en cuenta el producto anunciado, la marca a la que pertenece, la duración del spot, la presencia o ausencia de elementos navideños y los propios elementos.

- Clasificación. El método se ha basado en una concatenación de las categorías para determinar las partes frecuentes. De este modo, se han establecido las siguientes categorías: visuales (luces, árbol de Navidad, Papa Noel, Reyes Magos, regalos, familia, adornos...), textuales (mensajes con alusión a la Navidad) y auditivas (mensajes sonoros).

El diseño del método utilizado está basado en las pautas del autor Olabuenaga (1996, p. 205206):

- Las categorías han de estar construidas siguiendo un único criterio.

- Cada serie de categorías debe ser significativa.

- A su vez han de ser excluyentes.

- Las categorías tienen que ser significativas.

- Han de ser claras.

- Deben ser replicables.

- Pueden tener diferentes niveles.

\section{Técnicas del análisis de contenido}

Algunos autores describen el análisis de contenido como una técnica que se efectúa por medio de la codificación, «proceso en virtud del cual las características relevantes del contenido de un mensaje se transforman a unidades que permitan su descripción y análisis precisos" (Hernán- dez, Fernández y Baptista, 2003, p.413). Este tipo de estudio se basa en la lectura de mensajes como instrumento de recogida de información, una lectura que debe realizarse siguiendo el método científico.

El análisis de contenido se caracteriza por ser una práctica que combina intrínsecamente, de ahí su complejidad, la recogida y la producción de los datos con su interpretación y análisis. Para José Javier Sánchez (2005, p. 213), «la finalidad que perseguimos es acercarnos de una manera pertinente al objeto de estudio y sacar unas conclusiones que se adecúen lo más posible a lo que denominaríamos criterios de sentido común".

Este análisis de contenido se ha inspirado en las fases metodológicas propuestas por Enrique Bigné (1999, p.263): formular la hipótesis, definir la población objeto de estudio, seleccionar la muestra, seleccionar y definir la unidad de análisis, construir las categorías de contenido a analizar y establecer un sistema de cuantificación que dé lugar a la codificación, análisis de datos y elaboración de conclusiones.

\section{Protocolo}

El análisis de contenido como método científico de clasificación presenta indudables ventajas: es de fácil aplicación; produce resultados cuantificables; se puede extrapolar a mensajes mediáticos producidos en diferentes momentos temporales; puede utilizarse para abordar un gran volumen de información; se aplica directamente a los materiales, es decir, a las fuentes primarias de comunicación; puede aplicarse a una gran diversidad de productos; su valor depende de la calidad del investigador que diseña y utiliza el análisis de contenido; y frente a otras técnicas, su empleo es aceptable desde un punto de vista económico. Así mismo, cualquier análisis de 
contenido debe someterse a una normalización de sus procedimientos, una guía que Piñuel denomina «protocolo" y que reporta las siguientes garantías (Piñuel, 2002, pp. 17-18):

«Gracias a la existencia y manejo adecuado de un protocolo de análisis, suficientemente objetivado, si la misma muestra es analizada por investigadores diferentes, las conclusiones del estudio deben ser coincidentes. Igualmente, gracias a la existencia y manejo adecuado de un protocolo de análisis, suficientemente objetivado, si el mismo o diferentes investigadores estudian muestras diferentes pero igualmente representativas de los mismos procesos y sistemas de comunicación, también concluirán en semejantes resultados. Y, finalmente, gracias a la existencia y manejo adecuado de un protocolo de análisis, suficientemente objetivado, si el mismo o diferentes investigadores estudian muestras diferentes pero igualmente representativas de diferentes procesos y sistemas de comunicación, podrán llegar a conclusiones válidas tanto para comparar los procesos por su naturaleza, como por su evolución temporal".

El protocolo elegido implica la formulación del objetivo de la investigación, la conceptualización y operativización de las variables relevantes, la elaboración del libro de códigos y la ficha de análisis, así como el muestreo de los repertorios a analizar, la codificación de la muestra elegida, su posterior verificación, y por último, el análisis de los datos.

En base a lo anterior es conveniente explicar el procedimiento según el libro de códigos, en el que se establece:

- La naturaleza del corpus. La muestra se ha elegido en la etapa prenavideña para analizar los elementos propios de esta época del año porque la venta de esos productos está prevista para unos días después de su emisión, con lo que el grueso publicitario está condensado en la semana previa a las grandes fiestas. De la misma manera, se han elegido los anuncios alimenticios porque no existe ninguna investigación centrada en este tema (no sucede lo mismo en el campo de los juguetes, por ejemplo). El horario matutino y no vespertino y el canal elegidos ya han sido justificados en puntos anteriores. Con todo ello, se busca obtener conclusiones sobre la repetición de elementos comunes en esta publicidad tan estacional.

- En qué momento se debe abrir una ficha. El corpus se segmenta en función del cambio de anuncio. Para cada spot se abre una ficha nueva.

- Cómo ha de rellenarse la ficha. Los códigos alfanuméricos se detallan en el punto 4 . (Determinación de las reglas de codificación) dentro del apartado de metodología.

- Cuándo ha de cerrarse una ficha. Con la finalización del anuncio a analizar. Una vez concluida la recopilación de datos, las fichas han sido analizadas por fecha, de la misma forma que se han archivado.

- La base de datos. En función de lo anteriormente explicado, el punto de encuentro de las fichas está basado en la fecha de emisión del anuncio. En base a este criterio van a ser agrupadas.

- $\quad$ Plan de explotación. Del cruce de variables se pretende obtener conclusiones sobre la existencia de elementos comunes en la publicidad de istintas marcas alimentarias. No se ha aplicado en la presente investigación. 


\section{Desarrollo de la técnica}

\section{Ficha}

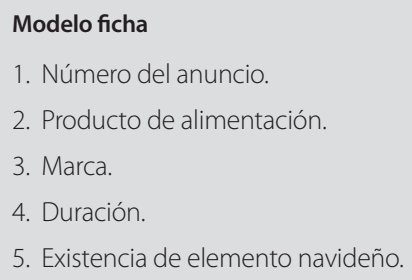

\section{Análisis}

Una vez determinado el objeto de estudio, las reglas de codificación y el sistema de categorías, se testó que las mismas fueran las adecuadas para eludir futuras ausencias a la hora de realizar el trabajo de campo. Dado que no se contaba con investigaciones anteriores sobre el tema el riesgo era mayor.

Tras ello, se procedió a la extracción de datos. Una vez recopilados se dio paso a la elaboración cuantitativa y cualitativa de los resultados que posteriormente se desarrollan. Tal y como señalan varios autores (Insch et al. 1997, Berg 1998, Robson, 2002; Neundorf, 2002; Collis y Hussey 2003) metodológicamente es correcto que el análisis de contenido puede utilizarse para dar lugar a ambos tipos de estudio.

Finalmente, a la luz de los hallazgos obtenidos, se extrajo una explicación analítica a modo de conclusión.

\section{Resultados}

\section{Cuantitativos}

Como muestra el Gráfico 1, el porcentaje de anuncios con patrones navideños (38\%) es inferior a aquellos que carecen de este tipo de elementos estacionales (62\%). Las campañas de marcas estacionales cuentan con patrones en la totalidad de los anuncios, mientras que tan sólo un $25 \%$ de los productos no estacionales reseñan el contexto navideño en sus spots.

Para aproximar al lector a los recursos navideños manejados por los anunciantes se ha deter-

\section{Gráfico 1 · Porcentaje de marcas con patrón/sin patrón}

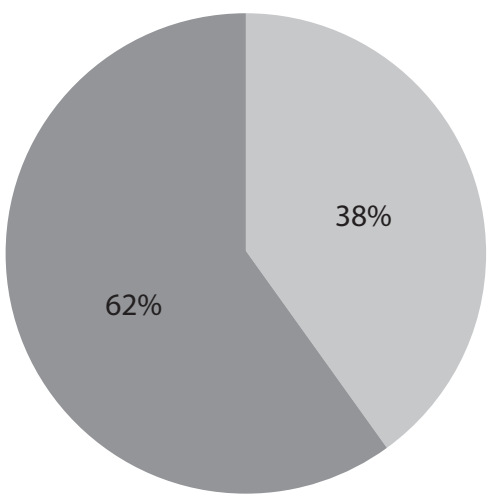

Con patrón

$\square$ Sin patrón 


\section{Tabla 1 • Porcentaje de aparición de los patrones navideños}

\begin{tabular}{|c|c|}
\hline Patrones & $\begin{array}{l}\text { Aparición en el total de marcas } \\
\text { anunciadas (\%) }\end{array}$ \\
\hline Árbol & 17,8 \\
\hline Luces & 14,2 \\
\hline Mesa & 10,7 \\
\hline Bolas & 8,9 \\
\hline Nieve & 7,1 \\
\hline Familia & 7,1 \\
\hline Velas & 5,3 \\
\hline Regalos & 5,3 \\
\hline Chimenea & 3,6 \\
\hline Lazo & 3,6 \\
\hline Acebo & 3,6 \\
\hline Papá Noel & 3,6 \\
\hline Espumillón & 1,7 \\
\hline Calcetines & 1,7 \\
\hline Corona & 1,7 \\
\hline Gorro & 1,7 \\
\hline Trineo & 1,7 \\
\hline Renos & 1,7 \\
\hline \multicolumn{2}{|c|}{ Fuente: elaboración propia. } \\
\hline
\end{tabular}

minado, en base a este estudio, una lista ordinal con los patrones visuales más utilizados (Tabla 1). Además, mediante el análisis de los elementos auditivos se ha advertido que el 91\% de los anuncios con patrones, independientemente de su estacionalidad, han utilizado voz en off o hilo musical, en algunos casos como apoyo a las imágenes y en otros como único referente a la Navidad. El porcentaje es el mismo si atendemos a los anuncios que tienen tanto elementos visuales como auditivos. Los elementos textuales son los menos utilizados por los anunciantes; tan sólo un $18,1 \%$ de los spots insertan frases escritas que hagan alusión a la Epifanía (Caldo Aneto y Carrefour - supermercado-).

Con todo esto ha de incluirse también un análisis temporal de los 127 anuncios estudiados. Durante la semana de investigación se emitieron aproximadamente 1.940 segundos de spots de alimentación, de los cuales 350 (18\%) corresponden a productos estacionales y 1.590 (82\%) a no estacionales. Si repartimos ese total de segundos entre aquellos que siguieron un patrón y los que no, nos encontramos con 860 $(44,3 \%)$ y $1.080(55,7 \%)$ segundos respectivamente. Estas diferencias son reseñables porque, si bien existe una emisión mayoritaria de productos alimenticios no estacionales, el uso de patrones navideños se intensifica durante las fiestas.

Al destacar los cuatro anuncios con más duración han de mencionarse, por orden, Casa Tarradellas (Pizza) y Coca-Cola con 30 segundos y Ferrero Rocher (bombones) y Philadelphia (queso para untar) con 25 segundos aproximadamente. Al otro lado de la balanza están Carrefour, Flor de Esgueva (queso), Gula del Norte y Hellmann's (mahonesa) con 5 segundos cada uno. Tan sólo uno de los mencionados corresponde a un producto estacional.

En cuestión de frecuencia, y partiendo de que se emitieron 127 anuncios de alimentación durante el periodo estudiado, el anuncio de Carrefour ha sido el más emitido (14 veces en la semana y horario analizados), seguido de Carretilla (espárragos) con 12, Gula del Norte con 11 y Ferrero Rocher con 9. Como puede observarse tenemos que bajar hasta la cuarta posición para encontrar el primer producto estacional en frecuencia de emisión. Por el contrario, los anun- 
cios con una única emisión y, por tanto, menos repetidos han sido: Hipercor (supermercado), Nescafé, Paladín a la taza (chocolate) y Turrón de
Suchard. Este hecho vuelve a situar a un producto estacional en un puesto inferior a los no estacionales (Gráfico 2).

\section{Gráfico 2 - Repetición de las marcas anunciadas (en nº de veces)}

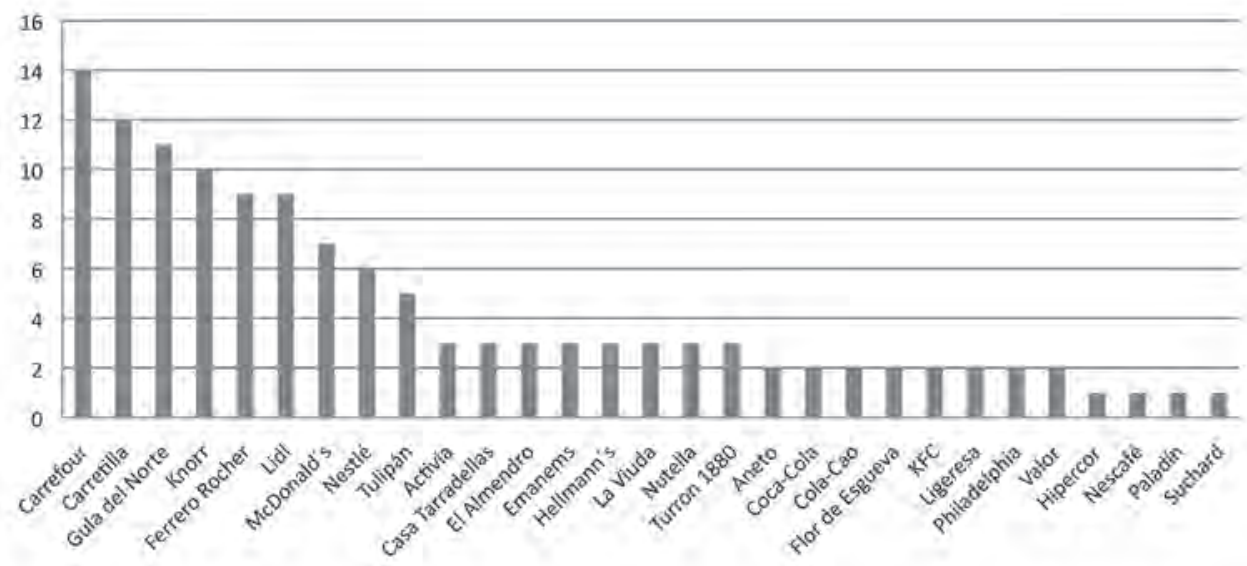

Fuente: elaboración propia.

\section{Gráfico 3 - Emisión de anuncios estacionales/no estacionales por día}

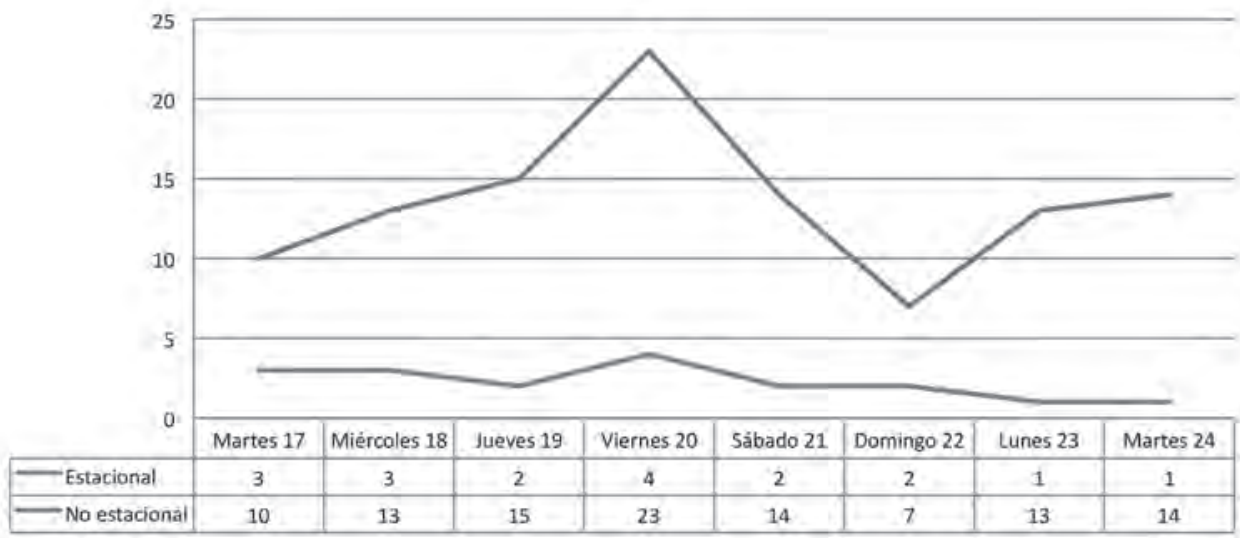


Así mismo y atendiendo a la emisión diaria de anuncios de alimentación, se han realizado los siguientes gráficos (Gráfico 3 y Gráfico 4) en función de la estacionalidad/no estacionalidad de los productos anunciados y de la presencial ausencia de patrones navideños en los mismos.

La máxima concentración de anuncios alimenticios en el periodo y horario estudiados se produce el viernes 20 de diciembre, que coincide con el día en que se emitieron no sólo más anuncios totales, sino la mayor cantidad de cada tipo. De esta manera se contabilizaron 23 emisiones de productos no estacionales y tan sólo 4 estacionales. En una segunda lectura podemos afirmar que es en esta jornada cuando existe una mayor diferencia entre ambos tipos de anuncios, pues en ninguno de los otros días la representatividad de los productos estacionales (14,8\%) había estado tan baja. Es decir, aunque hay más anuncios de productos típicos navideños, el porcentaje total es menor que en otras ocasiones, porque las emisiones de alimentos no estacionales son también muy superiores.

En cuanto al gráfico 4, la emisión de anuncios con y sin patrón no sigue una línea regular en el tiempo. Los anuncios sin patrón empiezan y acaban la semana de análisis con mayor representatividad que los anuncios con patrón. Sin embargo hay dos días, el sábado 21 y el domingo 22 de diciembre, en los que los spots con elementos navideños superan ligeramente a aquellos que carecen de ellos.

Por tanto, de estos dos gráficos obtenemos una información representativa: el fin de semana previo a las fechas señaladas de la Navidad es cuando más elementos y anuncios navideños se emiten.

\section{Cualitativos}

Para comprobar si existe o no un patrón entre marcas similares se han seleccionado 49 anuncios que a continuación se destacan en tres grupos:

\section{Gráfico 4 - Emisión de anuncios con patrón/sin patrón por día}

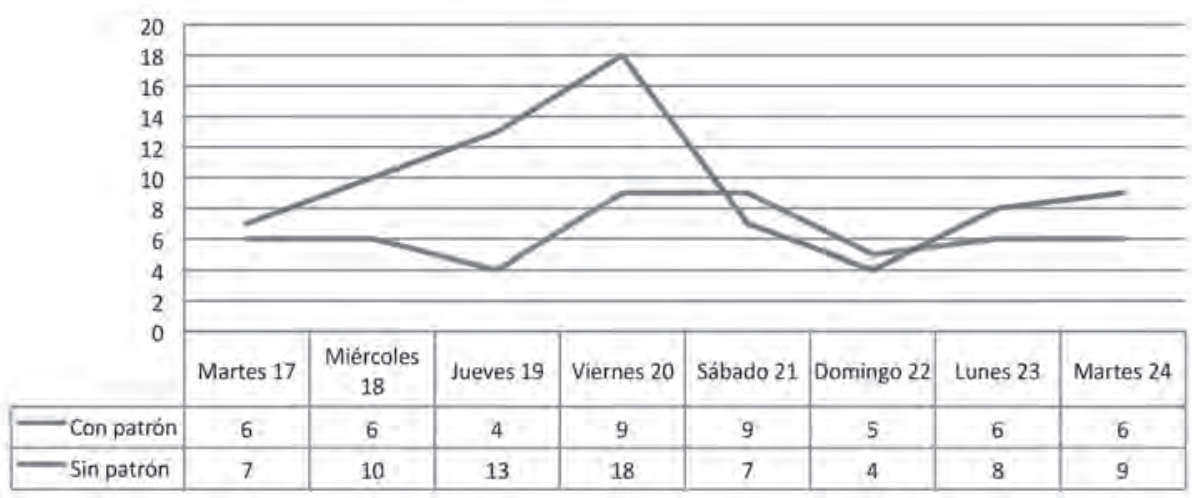


1. Supermercados. Se han incluido los anuncios de supermercados en el estudio porque el objeto de su publicidad eran los alimentos. Aquellos en los que no han aparecido productos comestibles no se han incorporado.

Durante la semana y horario seleccionado se ha emitido 24 veces la publicidad de los siguientes supermercados: Carrefour (14), Lidl (9) e Hipercor (1). Mientras que los dos primeros cuentan con patrones navideños, el último no. Esto supone que en más de un 90\% de los anuncios de supermercados emitidos se alude a la Navidad. No obstante, entre los elementos de ambos supermercados sólo coincide el uso de la nieve.

2. Bombones. Ha habido dos marcas que han acaparado el protagonismo en este sector; Ferrero, que anuncia un producto estacional, se ha emitido en 9 ocasiones y Nestlé en 6. El mercado de los bombones ha contado este año con la ausencia de Mon Cheri, curiosamente un producto de Ferrero Rocher, único anunciante que incorpora patrones navideños. Ante este hecho, no se puede comparar y concluir si las marcas de bombones utilizan patrones iguales o similares.

3. Turrones. Se han contabilizado las siguientes marcas: La Confitería de la Viuda, El Almendro, 1880 y Suchard. El 100\% ha incluido elementos visuales, el $80 \%$ ha sumado a ellos los auditivos (sólo no lo incluye 1880) y todos obvian las referencias textuales. En cuanto a la existencia de elementos comunes, se puede destacar que las cuatro marcas utilizan el árbol de Navidad y las luces. Tanto Turrón de Suchard, Confitería de la Viuda y 1880 recrean una situación de reunión en torno a una mesa. Además todas las marcas recuperan a la familia como parte central del anuncio, exceptuando el turrón 1880.
Si se ha mencionado la ausencia de una de las grandes marcas estacionales como es Mon Cheri, no se puede dejar de destacar que, tanto Nutella como Aneto y Activia, que no basan ni sus ventas ni sus productos en la Navidad, hayan decidido incluir patrones de esta época del año. El árbol es el objeto predominante en los spots de estas tres marcas.

\section{Conclusiones}

El estudio sobre publicidad alimentaria en periodo navideño arroja algunas conclusiones llamativas y dignas de reflexión:

En primer lugar, se ha constatado que la publicidad que incluye patrones navideños es ligeramente inferior a aquella que no los tiene, exceptuando el fin de semana. Así, más de un 60\% de las marcas publicitadas en la etapa de estudio están libres de elementos relacionados con esta época del año, frente al casi $40 \%$ que sí aprovechan la estacionalidad para introducirlos en sus campañas.

Estos datos pueden parecer lógicos, pues no todos los productos encajan en una tipología navideña ni todas las marcas consideran apropiado diferenciarse dependiendo de la época del año. No obstante, es significativo que el 25\% de los productos no estacionales (es decir, aquellos cuya producción y venta no están estratégicamente situadas en Navidad) recurran a elementos navideños. Cuando se trata de productos estacionales no hay ninguno que olvide, al menos de forma visual, los tópicos del ambiente de Pascua. En base a esto, podemos concluir que la hipótesis 2 (existe una diferenciación por estacionalidad. Aquellos que tienen un consumo anual no recurren a patrones propios de la Navidad) queda refutada.

Así como se ha reseñado que el 100\% de los productos estacionales (principalmente turro- 
nes) hacen alusión a la Navidad de forma visual, también incluyen otra tipología de elementos. Hasta en 4 de cada 5 anuncios (80\%), las imágenes están acompañadas de patrones auditivos. Principalmente se trata de canciones típicas, como los villancicos y, en un segundo modelo, se transmite una felicitación en voz en off. Es algo característico de los productos típicamente navideños, pues entre los no estacionales sólo se han encontrado dos ejemplos en los que ocurra esto: Carrefour (con un mensaje de Felices Fiestas) y Aneto. De nuevo vemos cómo la hipótesis 2 no es correcta.

En base al estudio se ha determinado que el patrón más repetido es el árbol de Navidad. De todos los anuncios que recurren a elementos navideños, es utilizado en un 17,8\% de las veces. Se puede concluir, por tanto, que el árbol de $\mathrm{Na}$ vidad es el objeto que los anunciantes ven como más representativo de las fiestas y es seguido muy de cerca (con un 14,2\%) de las luces, las reuniones en torno a una mesa $(10,7 \%)$ y las bolas (8,9\%), utilizadas como accesorio del árbol o como mero adorno navideño.

Por su parte, la familia y la nieve, aunque mantienen el protagonismo, han quedado por detrás en representatividad y congregan en torno al 7\% de las apariciones. Precisamente la repetición de la nieve hace pensar que en el imaginario colectivo los copos y las nevadas se consideran un símbolo de la Navidad. A continuación nos encontramos con las velas y los regalos (ambas un 5,3\%). Entre los menos utilizados destacan la chimenea, Papá Noel, el acebo (los tres con un 3,6\% de aparición) y adornos como lazos (también con un 3,6\%), espumillón, calcetines, corona tradicional, gorro de Papá Noel, el trineo y los renos (todos acumulan el $1,3 \%)$.
Es llamativo que la figura de los Reyes Magos, que en los anuncios de juguetes es muy utilizada, se haya visto totalmente anulada en el sector de la alimentación. No se ha contabilizado ni una sola aparición de lo que se puede considerar, a priori, un símbolo navideño por excelencia. En su lugar, parece que la figura de Papá Noel ha ganado protagonismo. También se ha percibido la falta de patrones como la planta de pascua o el muérdago.

Esto hace pensar que la publicidad alimentaria escribe un guión diferente de la de aquellos productos que tienen un sentido más comercial. En los patrones analizados y que tienen más éxito en los anuncios se denota una clara intención de apelar a los sentimientos y no tanto a los aspectos materiales. Es quizás por esto, por lo que lo familiar y tradicional tienen mayor relevancia. Por lo tanto, la hipótesis 1 (los anuncios navideños de alimentos recurren a situaciones en el hogar y tratan de evocar sentimientos familiares a través de unos patrones establecidos) queda confirmada.

Sin embargo, no todo se atiene a las reglas apriorísticas. Nutella y Activia, dos productos no estacionales, han incorporado la estrategia de los estacionales. Mientras que no es habitual encontrar publicidad con elementos navideños entre las marcas que dosifican su venta de forma anual, las dos que se han reseñado anteriormente han incluido, además de elementos visuales (bien es cierto, que en menor medida que los productos típicamente navideños), mensajes de audio. De nuevo, nos reafirmamos en que la hipótesis 2 no ha sido verificada.

Ambas han relacionado el momento de consumo con el producto anunciado de forma que Activia, por ejemplo, se ha presentado como el 
yogur indicado para hacer la digestión después de las grandes comidas.

A través de un estudio por sectores se puede concluir que los anuncios de turrones siguen patrones prácticamente iguales. Ya se ha comentado que el 100\% utilizan algún elemento navideño y que el $80 \%$ recurre además de a recursos visuales, a matices auditivos. A ello, hay que añadir que todas las marcas utilizan el árbol de Navidad y las luces como reclamos navideños, de la misma manera que el 90\% muestra situaciones familiares y de reunión. Es un intento por evocar sentimientos y olvidar el raciocinio. Las marcas de turrones intentan llegar al corazón de los consumidores y envuelven sus productos en un halo de felicidad y reencuentros. Afloran los sentimientos más emotivos y dotan al alimento del carácter festivo.

Es destacable que en el análisis por frecuencia de aparición tan sólo se ha contabilizado una vez al turrón de Suchard. Es llamativo que un producto tan estacional relegue su publicidad a un segundo plano durante la semana previa a las cenas y comidas por excelencia de estas fechas. Así mismo, de entre los cuatro anuncios más emitidos el único que corresponde a un producto estacional es Ferrero Rocher. Este hecho anula la hipótesis 3 (el grueso de la publicidad durante estas fechas señaladas está ocupado por anuncios de productos estacionales); no es cierto que la parrilla publicitaria se vea alterada por los productos más estacionales.

De esta lista se ha caído el bombón Mon Cheri, un clásico de otros años, que en diciembre de 2013 ha desaparecido del espacio publicitario en la franja de mañana de Telecinco.

Si se hace una medida en segundos y número de veces, los productos estacionales han sido menos anunciados que los no estacionales. Es un dato para reflexionar, pues el grueso de las ventas de turrones y bombones está delimitado por la Navidad. Ese hueco publicitario lo han cubierto las marcas no estacionales, que se han emitido tres veces más que las ya explicadas. En concreto han sido los supermercados los que más espacio publicitario han ocupado en el periodo estudiado. Esta misma información se corrobora en las tablas de emisión por día, donde podemos ver cómo la publicidad de marcas no estacionales es bastante superior a la de las estacionales. De nuevo, la hipótesis 3 se refuta.

Finalmente, en cuanto a la emisión de anuncios con patrones y sin patrones por día podemos concluir que es únicamente durante el fin de semana cuando los spots con patrones superan a los que carecen de ellos.

En definitiva, con esta investigación se ha constatado la importancia que cobra la vinculación de estas marcas con ciertos momentos puntuales que la publicidad escoge para hacer que el televidente se identifique con las mismas. Esta es una afirmación que se refuerza en el periodo navideño, cuando las reuniones en el hogar y la ambientación de los anuncios hacen que se evoquen sentimientos familiares a través de unos patrones determinados, logrando así que cuando el consumidor pasee por los stands de los supermercados asocie sus marcas con el momento representado en los spots. No obstante, estas estrategias no sólo forman parte de las marcas que únicamente se consumen en Navidad, sino que algunos productos de consumo anual adaptan su comunicación publicitaria a esta época del año. De esta forma es comprensible que, como se ha comprobado, el grueso de la publicidad no esté dedicado en exceso a los productos estacionales, sino que en el espectro publicitario se ha reservado un hueco para todas las marcas. 


\section{Bibliografía}

Abbatangelo-Gray, J.; Byrd-Bredbenner, C.; Austin, S.B. (2008). Health and nutrient content claims in food advertisements on Hispanic and mainstream prime-time television. Journal of Nutrition Education and Behavior, 40 (6), 348354.

Agencia de Publicidad 101 (2011). Evolución de los anuncios navideños en España. Extraído el 10 de diciembre de 2013 desde:

http://101.es/2011/12/la-evolucion-de-los-anuncios-navidenos -en-espana/\#axzz2qOBSQthM

Bardín, L. (1986): En análisis de contenido. Madrid: Ediciones Akal.

Berg, Bruce L. (1998). Qualitative Research for the Social Sciences. Boston: Allyn and Bacon.

Bigné, E. (1999). El análisis de contenido. En Metodología para la investigación en marketing y dirección de empresas (255-271). Madrid: Pirámide.

Byrd-Bredbenner, C. (2002). Saturday Morning Children's Television Advertising: A Longitudinal Content Analysis. Family E Consumer Sciences. Research Journal, 30 (3), 382403.

Collis y Hussey (2003). Business research. Hampsire: Palagrave MacMillan.

Consejo Audiovisual de Andalucía (2007). Estudio sobre la publicidad de juguetes en la campaña de Navidad 2006-2007. Extraído el 10 de diciembre de 2013 desde:

http://www.juntadeandalucia.es/institutodelamujer/ observatorio/html/campaigns/juegosyjuguetes/cont/docs/ Estudio_sobre_la_publicidad_200607

Consejo Audiovisual de Andalucía (2009). Estudio sobre la publicidad de juguetes en la campaña de Navidad 2008-2009. Extraído el 10 de diciembre de 2013 desde

http://www.consejoaudiovisualdeandalucia.es/sites/default/ files/publicaciones/estudio_publicidad_juguetes_2008-2009. pdf

Cortés de los Ríos, M. ${ }^{a}$ E. (2008). Estudio cognitivo del componente visual de mensajes publicitarios anunciados en la campaña de navidad. 25 Años de lingüística en España: Hitos y retos. R. Monroy y A. Sánchez, eds. 507-514.

Del Pino, A. (1991). La cara oculta de la publicidad. Cómo triunfar y pasarlo bien. Madrid: Ediciones Ciencias Sociales.
Eagle, L.; Bulmer, S.; De Bruin, A.; Kitchen, P.J. (2004). Exploring the link between obesity and advertising in New Zealand. Journal of Marketing Communications, 10 (1), 49-67. EFE/Barcelona. (2013, 25 de Diciembre). La 'estereotipada felicidad de los anuncios de Navidad (entrevista a Silvia Sivera). La Nueva España. Extraído el 27 de Diciembre de 2013 desde

http://www.lne.es/tv-espectaculos/2013/12/25/estereotipada -felicidad-anuncios-navidad/1519356.htm

Ferrer, M. (2007). Los anuncios de juguetes en la campaña de Navidad. Comunicar, 15 (29), 135-142.

Fueyo Gutiérrez, A. (2006-2007): El imaginario colectivo sobre el Sur, la solidaridad y la cooperación. Tabanaque. Revista Pedagógica, 20, 27-38.

Halford, J.C.G.; Boyland, E.J. (2012). The Marketing of Foods and Non-alcoholic Beverages to Children: Setting the Research Agenda. Appetite, 62, 182-184.

Hamilton-Ekeke, J.; Thomas, M. (2007). Primary children's choice of food and their knowledge of balanced diet and healthy eating. British Food Journal, 109 (6), 457-468.

Henderson, V.R; Kelly, B. (2005). Food Advertising in the Age of Obesity: Content Analysis of Food Advertising on General Market and African American Television. Journal of Nutrition Education and Behavior, 37 (4), 191-196.

Hernández, R.; Fernández, C.; Baptista, P. (2003). Metodolo-

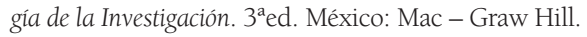

Insch, G.S.; Moore J.E.; Murphy, L. D. (1997). Content analysis in leadership research: Examples, procedures, and suggestions for future use. Leadership Quarterly, 8, 1-25.

Jaeger, S.R. (2006). Non-sensory factors in sensory science research. Food Quality and Preference, 17 (1-2), 132-144.

Just, D.R.; Payne, C.R. (2009). Obesity: can behavioral economics help? Annals of Behavioral Medicine, 38 (1), 47-55.

Krippendorff, K. (1990): Metodología del análisis de contenido: Teoría y práctica. Barcelona: Paidós.

Learman, S. (2011). Can Christmas advertising move past cliches? Extraído el 15 de diciembre de 2013 desde: http://www.youtube.com/watch?v=B0Jn8y-vt2Q León, J.L. (1991). Persuasión. En Diccionario de ciencias y técnicas de la comunicación (pp. 1.045-1.055). Madrid: Ediciones Paulinas. 
Marccía, J. (2000). Comunicación persuasiva para la sociedad de la información. Madrid: Universitas, S.A.

Nash, A.S.; Pine, K.J.; Messer, D.J. (2009). Television alcohol advertising: do children really mean what they say? British journal of developmental psychology, 27 (1), 85-104.

Neuendorf, K.A. (2002). The content analysis guidebook. Thousand Oaks, CA : Sage Publications.

Observatorio aea de la Publicidad (2012). Informe Televisión. Extraído el 9 de diciembre de 2013 desde:

http://www.anunciantes.com/descargas/20130314 _ 095624_InformeEjecutivoAnual2012.pdf OCU (2007, Marzo): Publicidad de alimentos en TV. OCU COMPRA MAESTRA, 313, 29-32.

Piñuel, J.L., 2002. Epistemología, metodología y técnicas del análisis de contenido. Estudios de Sociolingüística: Linguas, sociedades e culturas, 3 (1), 1-42.

Robson, C. (2002). Real World Research. Oxford: Blackwell Publishing.
Rubio, A (2011). La publicidad infantil en navidad: ¿fomentan la actividad y relaciones sociales? Revista Española de Comunicación en Salud, 2 (2), 69-77.

Ruiz Olabuenaga, J.I. (1996). Metodología de la investigación cualitativa. Bilbao: Universidad de Deusto.

Sánchez, J.J. (2005). Análisis de contenido cuantitativo de medios. En Investigar en Comunicación. Guía práctica de métodos y técnicas de investigación social en Comunicación (207228). Madrid: McGraw-Hill.

St-Onge, M.P.; Keller, K.L.; Heymsfield, S.B. (2003). Changes in childhood food consumption patterns: a cause for concern in light of increasing body weights. The American Journal of Clinical Nutrition, 78 (6), 1068-1073.

Story, M.; French, S. (2004). Food advertising and Marketing Directed at Children and Adolescents in the US. International Journal of Behavioral Nutrition and Physical Activity, 1, 3-20. 



\section{La comunicación \\ comercial en las monedas \\ Jetones publicitarios en \\ España (1886-1927)}

comercial

Communication in Coins

Advertising Jetons in Spain

(1886-1927)

Francisco Javier García Herrero Doctor en Ciencias de la Información Universidad de Valladolid

fjgherrero@yahoo.es
García, F.J. (2015). La comunicación comercial en las monedas: jetones publicitarios en España. Revista Internacional de Investigación en Comunicación aDResearch ESIC. № 11 Vol 11.

Primer semestre, enero-junio 2015. Págs. 96 a 117 DOI: 11.7263/ADRESIC.011.006 